\title{
Transient Elastography for the Diagnosis of Liver Fibrosis: A Systematic Review of
}

\author{
Economic Evaluations
}

\author{
Authors \\ Sasha van Katwyk ${ }^{1}$ \\ Doug Coyle 2,3 \\ Curtis Cooper ${ }^{1,4,5}$ \\ Kusala Pussegoda ${ }^{1}$ \\ Chris Cameron ${ }^{6}$ \\ Becky Skidmore ${ }^{1}$ \\ Stacey Brener ${ }^{7}$ \\ David Moher ${ }^{1,2}$ \\ Kednapa Thavorn*1,2, 8 \\ 1 Clinical Epidemiology Program, The Ottawa Hospital Research Institute, The Ottawa Hospital, Ottawa, \\ Ontario, Canada \\ 2 School of Epidemiology, Public Health and Preventive Medicine, University of Ottawa, Ottawa, Ontario, \\ Canada \\ 3 Health Economics Research Group, Brunel University London, Uxbridge United Kingdom \\ 4 Ottawa Hospital and Regional Hepatitis Program, The Ottawa Hospital, Ottawa, Ontario, Canada \\ 5 Department of Medicine, University of Ottawa, Ottawa, Ontario, Canada \\ 6 Evidence Synthesis Group, Cornerstone Research Group, Burlington, Ontario, Canada \\ 7 Health Quality Ontario \\ 8 Institute of Clinical and Evaluative Sciences (ICES Ottawa), Ottawa, Ontario, Canada
}

Authors' contributions: KT, DC, SB, CC and DM contributed to the conception of the study question and design. KP contributed to study screening and data abstraction processes. KT and SV refined methodologies for data analysis for the review, assessed the methodological quality of included studies and drafted the initial version of the manuscript. CC contributed to framing details of the clinical question and provided clinical expertise in development of the manuscript. BS derived the literature search strategy for the review. All authors reviewed and approved the manuscript.

Authors have no conflicts of interest to disclose.

This study was funded by an annual grant from the Heath Quality Ontario (HQO). The opinions, results, and conclusions reported in this paper are those of the authors and are independent from the foregoing organization. No endorsement by HQO is intended or should be inferred.

- Our systematic review includes four cost-utility and four cost-effectiveness analyses of transient elastography (TE) for the diagnosis of liver fibrosis in patients living with chronic liver diseases.

- Included cost-utility analysis studies show that TE is cost-effective for hepatitis B and cost-savings for hepatitis $\mathrm{C}$ patients compared to liver biopsy and other non-invasive tests.

- Included cost-effectiveness studies reveal that TE incurs lower costs but also provides fewer accurate diagnoses compared to liver biopsy.

- The methodological quality of the included studies varies. Most studies fail to describe and justify input parameters used for their economic models and sensitivity analyses 
Main Body Word Count: 4,005

Number of Figures: 4

Number of Tables: 3

List of Abbreviations:

NAFLD: non-alcoholic fatty liver disease

ALD: alcoholic liver disease

TE: transient elastography

ARFI: acoustic radiation force impulse

CAP: controlled attenuation parameter

QALY: quality-adjusted life years

ICER: incremental cost-effectiveness ratio

HTA: health technology assessment

NILT: non-invasive liver test

CHEERS: $\quad$ Consolidated Health Economic Evaluation Reporting Standards

\section{*Corresponding Author}

Kednapa Thavorn, $\mathrm{PhD}$

The Ottawa Hospital-General Campus, 501 Smyth Road, PO Box 201B, Ottawa, Ontario, Canada K1H 8L6.

E-mail: kthavorn@,ohri.ca

Tel: 613-737-8899 ext 72330

\section{Abstract}

Background: Liver biopsy remains the gold standard for the diagnosis of liver fibrosis, but its use as a diagnostic tool is limited by its invasive nature and high cost.

Objective: To systematically review the cost-effectiveness of transient elastography (TE) with and without controlled attenuation parameter (CAP) for the diagnosis of liver fibrosis or steatosis in patients with hepatitis B, hepatitis C, alcoholic liver disease, and non-alcoholic fatty liver disease.

Methods: An economic literature search was performed using computerized databases. Eligibility criteria included systematic reviews, health technology assessments, or economic evaluations of TE compared to liver biopsy and other non-invasive tests. After abstract screening, full-text reports of 
potentially relevant articles were assessed in duplicate. The methodological quality of the included studies was also appraised.

Results: The database search yielded 253 records; four cost-effectiveness and four cost-utility studies were included. The methodological quality of the included studies varies. High quality costeffectiveness studies suggested that TE is less costly but also less accurate than liver biopsy. The cost-effectiveness ratio of TE improves with a greater level of diagnostic accuracy and a higher degree of liver fibrosis. Based on high-quality cost-utility studies, TE is a cost-effective alternative to biopsy with incremental cost-effectiveness ratios between $\$ 9,000$ per QALY and $\$ 14,000$ per QALY. We did not find studies that assessed the cost-effectiveness of TE with CAP for the diagnosis of liver steatosis.

Conclusions: TE is an economically attractive alternative to liver biopsy and other non-invasive diagnostic tests especially for patients with hepatitis B and C.

\section{Abstract Word Count: 249 \\ Keywords: Transient elastography, controlled attenuation parameter, liver fibrosis/steatosis, chronic liver disease, systematic review, health economic evaluation}

\section{Background}

Liver disease is estimated to affect over 500 million people worldwide (1). Advanced stages of liver disease can often result in liver fibrosis which is characterized by excessive accumulation of extracellular matrix protein. The most common causes of liver fibrosis are hepatitis B, hepatitis C, non-alcoholic fatty liver disease (NAFLD), alcoholic liver disease (ALD), and cholestatic liver disease. Chronic viral hepatitis (including hepatitis B and C), fatty liver disease, and liver cancer alone are responsible for nearly $95 \%$ of deaths from liver disease. (1) 
Early stages of fibrosis are observable and often treatable; however, gone unchecked, it can lead to cirrhosis, portal hypertension, liver cancer and liver failure. (2) The only curative treatment for latestage cirrhosis is liver transplant. Accessible and accurate diagnosis in early stages of liver disease is therefore crucial as it can predict disease prognosis, prevent disease progression, improve patient health outcomes, and reduce healthcare costs.

Liver biopsy is the current gold standard for assessing the degree of fibrosis and steatosis, though its diagnostic accuracy is in question. Fibrosis is rarely uniform across the liver, compromising the efficacy of a biopsy that has the risk of penetrating a yet to be affected area. (3) Insufficient amount of biopsy material may lead to inaccurate staging. Additionally, the method of scoring potential fibrosis has been shown to suffer from inter-observer variation, leading to false diagnosis or the need for additional tests. (4) This diagnostic technique is also invasive, compelling many candidates to refuse the procedure, and has been associated with complications including frequent discomfort and rarely bleeding and mortality. (5)

Alternative non-invasive diagnostic techniques, such as transient elastography (TE), FibroTest, and acoustic radiation force impulse (ARFI), have been considered as substitutes to liver biopsy. TE (brand name: FibroScan) is used to measure liver stiffness. (6) TE is a non-invasive method that can be performed at the bedside or in an outpatient clinic (7) that can be paired with controlled attenuation parameter (CAP) to detect liver steatosis (8). FibroTest is a composite calculated score of five serum biochemical markers. A Canadian survey published in 2014 found that $46.2 \%$ of physicians who manage patients with liver disease used liver biopsy as the primary diagnostic tool for assessing fibrosis, followed by TE (39.4\%) and Fibro'Test (7.7\%). 42.7\% of surveyed physicians 
believed that the need for liver biopsy could be reduced by at least $50 \%$ if non-invasive diagnostic methods were made more available. (9)

Non-invasive diagnostic methods are available and adopted in several countries; however, lack of public coverage often limits access to these services. As rising spending on health continues to put pressure on public budgets, health economic evaluation can be used as an explicit approach to help guide resource allocation decision. This study was therefore conducted to systematically summarize studies that assessed the cost-effectiveness of TE compared to liver biopsy and other non-invasive tests in patients living with chronic liver diseases.

\section{Methods}

A systematic review of health economic evaluation studies comparing TE to liver biopsy and/or other non-invasive tests was conducted.

\section{$\underline{\text { Information Sources }}$}

An experienced information specialist produced and tested preliminary electronic search strategies using an iterative process in collaboration with the research team. Using the OVID platform, an economic literature search was performed in Ovid MEDLINE® In-Process \& Other Non-Indexed Citations and Ovid MEDLINE® and Embase Classic+Embase on November 26th, 2014. The Cochrane Library (HTA database, NHSEED, DSR, DARE, and CENTRAL) was searched on November 26, 2014. There were no restrictions on any of the search strategies. Full search strategy details are shown in Appendix A. Several websites of relevant organizations were searched as sources for grey literature, including the Canadian Agency for Drugs and Technologies in Health, 
the Institute of Health Economics, the National Institute for Health and Care Excellence, EuroScan, and the Centre for Reviews and Dissemination database.

\section{$\underline{\text { Eligibility Criteria }}$}

English or French language full-text publications that met inclusion criteria were included in the review. The relevant patient population included those with hepatitis B, hepatitis C, non-alcoholic fatty liver disease (NAFLD), alcoholic liver disease (ALD), or other chronic liver disease.

Interventions under review were TE compared to liver biopsy, FibroTest, or ARFI. Searches also included comparison of TE with CAP to liver biopsy in the diagnosis for liver steatosis. Outcomes of interest were cost-effectiveness measures where effectiveness was determined either through the number of correctly identified cases or quality-adjusted life years (QALYs). In cases where an

incremental cost-effectiveness ratio (ICER) was not explicitly provided, cost and effectiveness were derived from the reported findings. The design of an eligible study included systematic reviews of economic evaluation, health technology assessment (HTA) reports, or full economic evaluations that compared both costs and outcomes of TE without or with CAP to liver biopsy, Fibro'Test, or ARFI. We did not limit inclusion by year of publication.

\section{$\underline{\text { Screening and Selection }}$}

Citations were de-duplicated in Reference Manager (Thomson Reuters, New York, NY). Data Management software, DistillerSR ${ }^{\circledR}$, was used to manage retrieved records, screen reports, identify and track disagreements and to store extracted data. Titles and abstracts were screened by one reviewer $(\mathrm{KP})$ for potential relevance; a second reviewer $(\mathrm{KT})$ verified records that were deemed not relevant. The full-text reports of potentially relevant records were reviewed independently by two reviewers (KP and KT). Disagreements between reviewers during full-text screening were resolved via consensus. Co-publications or multiple reports of the same study were identified as such. 


\section{$\underline{\text { Data Abstraction and Data Collection Process }}$}

Articles were abstracted by one member of the research team (KP) and verified by a second member (SV). Disagreements were resolved through consensus. We abstracted study characteristics, including study design, study location (and respective currency), modelling method (e.g. decision tree or Markov), the study's eligible population, and intervention/comparator (TE, liver biopsy, FibroTest, ARFI, or different diagnostic modalities for the same technology). For systematic reviews of economic evaluation, the number of included studies was also abstracted. The perspective of the economic evaluation was categorized as: patient, hospital, health care system, or society.

Results of cost-effectiveness studies were reported as an incremental cost effectiveness ratio (ICER), which was derived by dividing the difference in cost between TE and the comparator (incremental cost) by the difference in effectiveness of TE and the comparator (incremental effectiveness).

\section{Methodological quality appraisal}

The methodological quality of the included studies was appraised using the 10-item Drummond checklist (10). This tool is commonly used and recommended by the Cochrane Collaboration for assessing the quality of health economic evaluation studies. (11) Each study was appraised independently by two team members (SV and KT). Any conflicts were resolved through discussion

and consensus. A score of eight or higher (out of ten) indicated that the study was methodologically sound and made a concerted effort to describe the nature of the study in rigorous detail. (11).

\section{$\underline{\text { Synthesis }}$}


The results of included studies were reported narratively. Cost data from each included study was converted to 2015 U.S. Dollars (USD) using purchasing power parity for the year of each study then adjusted for inflation to the year 2015. (12)

\section{Results}

$\underline{\text { Literature search and screening }}$

The database search yielded 242 records published before March 9, 2015 (with duplicates removed). An additional 11 records were identified by bibliographic search. Of the 253 independent records retrieved, 68 studies were reviewed for eligibility at full text. Eight studies were included in qualitative synthesis, two of which were companions to an included study (Figure 1).

\section{$\underline{\text { Study and patient characteristics }}$}

A summary of the characteristics of the eight included studies is presented in Table 1. All eight studies assessed the cost-effectiveness of TE compared to liver biopsy and other non-invasive tests in the diagnosis, staging, and monitoring of liver fibrosis associated with hepatitis $\mathrm{C}$, hepatitis $\mathrm{B}$, ALD, or NAFLD. Four studies performed a direct comparison of TE, other non-invasive methods, and liver biopsy. Two studies compared different diagnostic modalities whereby different diagnostic tests and disease management strategies, such as treat none and treat all, were compared. Four studies conducted a health economic evaluation alongside a systematic review, and two of the included studies were primary cost-effectiveness analyses. These studies were conducted between 2009 and 2015 and took place in the United Kingdom (five studies), Canada (two studies), and the United States (one study). Four studies were conducted from the perspective of the health care system, and two studies were from the perspective of the hospital. The majority of the included studies (six out of eight) included HCV-infected patients as a population of study. 


\section{Methodological quality appraisal}

Figure 2 presents the score distribution across each of the 10-item Drummond checklist according to whether or not the study fulfilled the criterion (or was not applicable) in terms of study design, execution, and reporting of relevant information on the nature and methods of the study. There was a high variability in methodological quality and comparability of the included studies. The scores varied from 5 to 9 out of a possible 10. Three studies $(14,17,19)$ had a score of eight or higher. Most studies failed to adequately describe and justify the resources utilized (Item 5) and adequately address for uncertainty (Item 9). Most studies provided tables of sources utilized; however, only two $(14,19)$ studies provided detailed description of data sources and justification for input parameters used in the model. All studies performed a sensitivity analysis, albeit varied in design (Table 2). Only two studies $(14,17)$ provided adequate justification for the ranges employed in the sensitivity analysis and offered clear reasoning for how variance in the parameters impacted the final conclusions.

The type of sensitivity analyses reported varied among included studies and the chosen analysis type were not consistent with any particular model type or set of parameters. The more rigorously reported sensitivity analyses $(14,17)$ found that the sensitivity and specificity of the TE was the key driver of cost-effectiveness results.

\section{$\underline{\text { Effectiveness, cost and cost-effectiveness results }}$}

Table 3 displays the results of the included studies by effectiveness, cost, and cost-effectiveness results. 
We found that there was variability in conclusions on the effectiveness of TE compared to liver biopsy across liver disease type and severity. Studies that compared diagnostic effectiveness across various stages of liver fibrosis $(F \geq 2, F \geq 3, F=4)$ found a congruent positive correlation between TE's diagnostic accuracy and increased severity of fibrosis. This correlation translated to costeffectiveness, with a more favourable ICER among more severe cases of fibrosis. (14-19) Compared to liver biopsy, TE was associated with a decreased diagnostic accuracy, ranging from $8 \%$ to $26 \%$. Several studies found that TE became dominant—costing less and was at least as effective as biopsy - in cases of severe liver fibrosis $(\mathrm{F}=4)$ where TE diagnostic accuracy is much higher. (14, 15)

\section{Cost results}

Table 3 presents the costs of diagnostic tests reported in each included study. Different perspectives of analysis and health care systems precluded quantitative synthesis. Of the five studies from the United Kingdom, two provided unit costs for the diagnostic tests. TE was priced at $\$ 20.78$ from the health care system's perspective (15) and $\$ 73.30$ (19) from the hospital's perspective. The cost of liver biopsy was $\$ 951.78$ from the perspective of health care system (15) and ranged from $\$ 1311.10$ to $\$ 2,199.83$ from the perspective of the hospital (19). The two Canadian studies (a primary study and its companion) $(13,17)$ reported the cost of diagnostic tests from the health care system perspective (Table 3, row 1). The United States study used the hospital perspective and estimated the cost of TE to be $\$ 145.75$ per evaluation compared to liver biopsy at $\$ 1,396$ per evaluation (Table 3, row 4) (16).

\section{Cost-effectiveness results}


We report the cost-effectiveness results in sub-sections according to the type of health economic evaluation: cost-effectiveness studies with a short-term outcome (cost per correct diagnosis) and cost-utility analysis with a long-term outcome (QALY).

\section{Cost-effectiveness studies with a short-term outcome}

Four studies $(13,15-17)$ performed a cost-effectiveness analysis of TE and presented an incremental cost per one correct diagnosis of TE compared to biopsy. These studies consistently showed that TE incurred lower costs but also provided fewer accurate diagnoses compared to liver biopsy. One study (17) found the cost of liver biopsy compared to TE was between $\$ 1,712$ and $\$ 8,768$ per correct diagnosis due to the lower cost of TE, while two other studies $(15,16)$ determined that the cost per correct diagnosis for TE compared to biopsy ranged between $\$ 1,250$ and $\$ 2,922$. Plotting these incremental cost-effectiveness ratios to a cost-effectiveness plane (Figure 3), TE would fall into quadrant three (Q3) of the cost-effectiveness plane, suggesting that TE was less effective but also less costly test. One study (15) also compared the cost-effectiveness of TE to FibroTest and found that an incremental cost-effectiveness ratio of TE was $\$ 666.66$ per an additional case of correct diagnosis and that TE dominated Fibro'Test in patients with severe (F4) fibrosis.

Figure 4 summarizes the findings of the high quality cost-effectiveness studies (a score of eight or higher). While there is some variation in the studies' interpretations based on varied treatment scenarios, a general trend is visible that as the fibrosis becomes more severe TE is more cost effective. Also uniquely visible from this summarized data is that the variance in findings is significantly smaller in HCV patients, which is largely due to consistence in favorable effectiveness of TE in these patients across included studies. Finally, in the case of NAFLD and CLD, TE was always cost-effective or dominant at the highest severity of fibrosis $(F=4)$. 


\section{Cost-utility studies with long-term outcomes}

Nearly all studies performing cost-utility analysis consistently argued that TE would be more costeffective when long-term health care costs were taken in to account $(14,15,17-19)$. This was a more pronounced finding when taking the perspective of the health care system, as these studies included a wider range of costs associated with later stage fibrosis, including out-of-hospital costs that were otherwise averted due to early diagnosis. $(14,15,17)$

Four studies $(14,18-20)$ conducted a cost-utility analysis of TE and reported an incremental cost per QALY gained. We observed unique findings for studies evaluating long-term costs and consequences of diagnostic testing strategies. Stevenson et al. (2012) devised a decision model and estimated the incremental cost and effectiveness of TE, Fibro'Test, and FibroMAX compared to the gold standard liver biopsy in ALD patients. Of the scenarios that did stand to sensitivity analysis, TE

was found to be the only cost effective alternative to biopsy when the hospital utilized a triage policy whereby patients with positive non-invasive liver test (NILT) would receive a biopsy. Canavan et al. (2013) performed a cost-utility analysis compare of various diagnostic policies that varied the use of TE compared to liver biopsy over different time periods. The authors concluded that the optimal tested strategy was an annual TE scan for all those with hepatitis C, generating an ICER of \$9,616 per QALY over the best next strategy - symptomatic investigation and treatment with no fibrosis surveillance or HCC screening. Crossan et al. (2015) performed a cost-effectiveness of non-invasive tests, including TE, Fibro'Test, and ARFI, compared to liver biopsy. They concluded that it is costeffective to treat all hepatitis C patients without prior testing for liver fibrosis $(\$ 13,176$ per QALY). For patients living with $\mathrm{HBeAg}$-positive, the most cost effective option was TE performed 
sequentially with another non-invasive diagnostic test; however, the results had high uncertainty. For ALD patients, liver biopsy was found to be the most cost-effective option ( $\$ 1,177$ per QALY).

All cost-utility studies performed a scenario analysis that found at least one diagnostic protocol scenario in which TE was more cost-effective than biopsy based on a willingness to pay threshold of $\$ 22,000$; however, diagnostic modalities used in sensitivity analyses for each study were very different suggesting high uncertainty in cost-effectiveness findings. All four studies did conclude that TE was the most cost-effective option compared to other non-invasive diagnostic tests.

At the time of writing, we did not find economic evaluation studies that assessed the costeffectiveness of TE with CAP in diagnosing liver steatosis.

\section{Discussion}

Our review highlights that TE is economically attractive compared to liver biopsy in cases where the diagnostic test is used to confirm suspected severe fibrosis $(F \geq 3$ to $F=4)$. In cases of severe liver fibrosis and cirrhosis $(\mathrm{F}=4)$, diagnostic accuracy of TE and liver biopsy are extremely comparable; however, the cost of TE is much lower. The disproportionate change in an incremental effectiveness compared to a difference in cost between TE and biopsy leads to TE becoming more cost-effective with more severe stage of fibrosis. Based on the highest methodological quality studies (scored eight or higher), we conclude that TE is a cost-effective non-invasive diagnostic alternative to biopsy with an ICER between $\$ 9,000$ per QALY and $\$ 14,000$ per QALY.

TE was cost-effective when it was included in the annual liver fibrosis screening modality for patients with hepatitis C. This is perhaps due to the higher risk of fibrosis progression among patients with hepatitis C. (21) Results of included studies comparing TE to other non-invasive 
diagnostic methods were consistent in finding that TE was a cost-effective option because it had comparable cost but higher diagnostic accuracy.

Half of the included studies performed a cost-effectiveness analysis and expressed their costeffectiveness outcomes as an incremental cost per one correct diagnosis. This measure is helpful in cases that TE is less costly and more accurate because it allows decision makers to identify the most accurate diagnostic test with the lowest cost. However, in the case that TE is less costly but also less accurate or more expensive but more accurate, one must apply the maximum that decision makers are willing to pay to improve one additional unit of outcome. Since there is no standard threshold for cost per accurate diagnosis outcome, it is still unclear whether TE is cost-effective based on short-term cost-effectiveness results. Although the use of cost-effectiveness thresholds is controversial, several developed countries have used them guide funding decisions for new health technologies. For example, the United Kingdom uses a threshold range of $£ 20,000$ to $£ 30,000$ per QALY gained, (22) and the United States uses a value of \$50,000 per QALY gained. (23) In Canada, commonly used thresholds range from $\$ 20,000$ to $\$ 100,000$ per QALY gained. (24)

Most of the included studies $(15-17,19)$ reported only partial findings to their research question. While this is surprising, partial reporting is a regular shortcoming across a wide variety of biomedical research (25). Variation in study designs and sensitivity analyses created a challenge for us in sussing out the evidence from these six included studies. In part, this was due to under-reporting of key model design features and data source justifications. This made direct comparison of findings problematic as we could not always determine how final values were obtained or how the cost and effectiveness of TE was derived. 
Variation in methods and reporting in economic evaluation forces knowledge users to derive their own interpretation of the study findings. Inconsistency in methods can lead to misinterpretation and under-utilization of the evidence by policy makers and health care practitioners. To facilitate the use of economic evaluation in guiding decision about resource allocation, future studies should adhere to good research practices (26) and reporting guideline, such as the Consolidated Health Economic Evaluation Reporting Standards (27).

\section{Limitations}

This review should be interpreted in light of the following limitations. First, this study focused on the cost-effectiveness of TE relative to liver biopsy and few non-invasive diagnostic tests. While some non-invasive tests were captured (AFRI and FibroTest), many other tests are available on the market and were not included in this study. Second, this systematic review was limited to studies published in English or French. Given TE is widely used in many European countries, it is possible that the evidence about TE included in this review is under-represented. Finally, our review synthesized the results of health economic evaluation conducted in various countries and health care systems. The interpretation of our results should be interpreted with caution because the application of our findings may depend on cost-effectiveness thresholds, budgets and reimbursement mechanisms.

\section{Conclusions}

TE was the most favourable non-invasive alternative to liver biopsy as it was cost-saving and yielded the highest diagnostic accuracy. Compared to liver biopsy, TE was cost-saving for diagnosis liver fibrosis in patients with hepatitis $C$ and cost-effective for diagnosis of fibrosis in patients with 
hepatitis B. Further research is needed to show the cost-effectiveness of TE in patients living with ALD and NAFLD and the cost-effectiveness of TE with CAP in the diagnosis of liver steatosis.

\section{Acknowledgements}

The authors are pleased to acknowledge Roxanne Ward, Mona Ghannad, and Raymond Daniel who provided valuable supports throughout the study. 


\section{References}

1. Canadian Liver Foundation. Liver disease in Canada: a crisis in the making [Internet]. Toronto: Canadian Liver Foundation, 2013 Mar [cited 2015 Mar 7]. p.71

2. Benvegnu L, Gios M, Boccato S, Alberti A. Natural history of compensated viral cirrhosis: a prospective study on the incidence and hierarchy of major complications. Gut. 2004;53(5):744-9.

3. Regev A, Berho M, Jeffers LJ, et al. Sampling error and intraobserver variation in liver biopsy in patients with chronic HCV infection. Am J Gastroenterol. 2002;97:2614-2618.

4. Standish, R. A., Cholongitas, E., Dhillon, A., Burroughs, A. K., \& Dhillon, A. P. (2006). An appraisal of the histopathological assessment of liver fibrosis. Gut, 55(4), 569-578. doi:10.1136/gut.2005.084475

5. West J, Card T. Reduced mortality rates following elective percutaneous liver biopsies. Gastroenterology. 2010;139:1230-1237.

6. Sandrin L, Fourquet B, Hasquenoph JM, Yon S, Fournier C, Mal F, et al. Transient elastography: a new noninvasive method for assessment of hepatic fibrosis. Ultrasound Med Biol. 2003;29(12):1705-13.

7. Murtagh J, Foerster V. Transient elastography (FibroScan) for non-invasive assessment of liver fibrosis. Ottawa (ON): Canadian Agency for Drugs and Technologies in Health; 2006.

8. Myers RP, Pollett A, Kirsch R, Pomier-Layrargues G, Beaton M, Levstik M, et al. Controlled attenuation parameter (CAP): a noninvasive method for the detection of hepatic steatosis based on transient elastography. Liver Int. 2012;32(6):902-10.

9. Sebastiani G, Ghali P, Wong P, Klein MB, Deschenes M, Myers RP. Physicians' practices for diagnosing liver fibrosis in chronic liver diseases: a nationwide, Canadian survey. Can J Gastroenterol Hepatol. 2014;28(1):23-30. 
10. Drummond M, Schulpher M, Torrance G, O’Brien B, Stoddart G. Methods for the Economic Evaluation of Health Care Programmes. $3^{\text {rd }}$ ed. Oxford, New York: Oxford University Press. 2005.

11. Higgins, J. \& Sally Green (2011) Cochrane Handbook for Systematic Reviews of Interventions. The Cochrane Collaboration; Version 5.1.0

12. OECD. StatExtracts, PPPs and exchange rates. <http://stats.oecd.org/Index.aspx?datasetcode=SNA_TABLE4>

13. Steadman R, Myers RP, Leggett L, Lorenzetti D, Noseworthy T, Rose S, et al. A health technology assessment of transient elastography in adult liver disease. Can J Gastroenterol. 2013;27(3):149-58.

14. Crossan C, Tsochatzis EA, Longworth L, Gurusamy K, Davidson B, Rodriguez-Peralvarez M, et al. Cost-effectiveness of non-invasive methods for assessment and monitoring of liver fibrosis and cirrhosis in patients with chronic liver disease: systematic review and economic evaluation. Health Technol Assess. 2015;19(9):1-410.

15. Centre for Evidence-based Purchasing. Cost-effectiveness of ultrasound elastography in the assessment of liver fibrosis. York (UK): National Health Service; 2009. p.35

16. Carlson JJ, Kowdley KV, Sullivan SD, Ramsey SD, Veenstra DL. An evaluation of the potential cost-effectiveness of non-invasive testing strategies in the diagnosis of significant liver fibrosis. J Gastroenterol Hepatol. 2009;24(5):786-91.

17. Steadman R, Leggett L, Lorenzetti D, Noseworthy T, Rose S, Sutherland L, et al. Health technology assessment of transient elastography in liver disease. Calgary (AB): University of Calgary Health Technology Assessment Unit; 2012. 180 
18. Canavan C, Eisenburg J, Meng L, Corey K, Hur C. Ultrasound elastography for fibrosis surveillance is cost effective in patients with chronic hepatitis C virus in the UK. Dig Dis Sci. 2013;58(9):2691-704.

19. Stevenson M, Lloyd-Jones M, Morgan MY, Wong R. Non-invasive diagnostic assessment tools for the detection of liver fibrosis in patients with suspected alcohol-related liver disease: a systematic review and economic evaluation. Health Technol Assess. 2012;16(4):1-174.

20. Tsochatzis EA, Crossan C, Longworth L, Gurusamy K, Rodriguez-Peralvarez M, Mantzoukis K, et al. Cost-effectiveness of noninvasive liver fibrosis tests for treatment decisions in patients with chronic hepatitis C. Hepatology. 2014;60(3):832-43.

21. D’Amico G, Garcia-Tsao G, Pagliaro L. Natural history and prognostic indicators of survival in cirrhosis: a systematic review of 118 studies. J Hepatol 2006;44:217-31.

22. Culyer A, McCabe C, Briggs A, Claxton K, Buxton M, Akehurst R, et al. Searching for a threshold, not setting one: the role of the National Institute for Health and Clinical Excellence. J Health Serv Res Policy 2007;12(1):56-8.

23. Hirth RA, Chernew ME, Miller E, Fendrick AM, Weissert WG. Willingness to pay for a quality-adjusted life year: in search of a standard. Med Decis Making 2000;20(3):332- 42.

24. Laupacis A, Feeny D, Detsky AS, Tugwell PX. How attractive does a new technology have to be to warrant adoption and utilization? Tentative guidelines for using clinical and economic evaluations. CMAJ. 1992 Feb 15;146(4):473-81.

25. Macleod MR, Michie S, Roberts I, Dirnagl U, Chalmers I, Ioannidis JPA, Al-Shahi Salman R, Chan AW, Glasziou P. Biomedical research: increasing value, reducing waste. The Lancet, 2014:383(9912):101-4. 
26. Ramsey SD, Wilke RJ, Briggs AH, et al. Good Research Practices for Cost-Effectiveness Analysis Alongside Clinical Trials: The ISPOR RCT-CEA Task Force Report. Value Health $2005 ; 8: 521-33$.

27. Husereau D, Drummond M, Petrou S, Carswell C, Moher D, Greenberg D, Augustovski F, Briggs AH, Mauskopf J, Loder E; Consolidated Health Economic Evaluation Reporting Standards (CHEERS)--explanation and elaboration: a report of the ISPOR Health Economic Evaluation Publication Guidelines Good Reporting Practices Task Force. Value Health. 2013 Mar-Apr;16(2):231-50. 


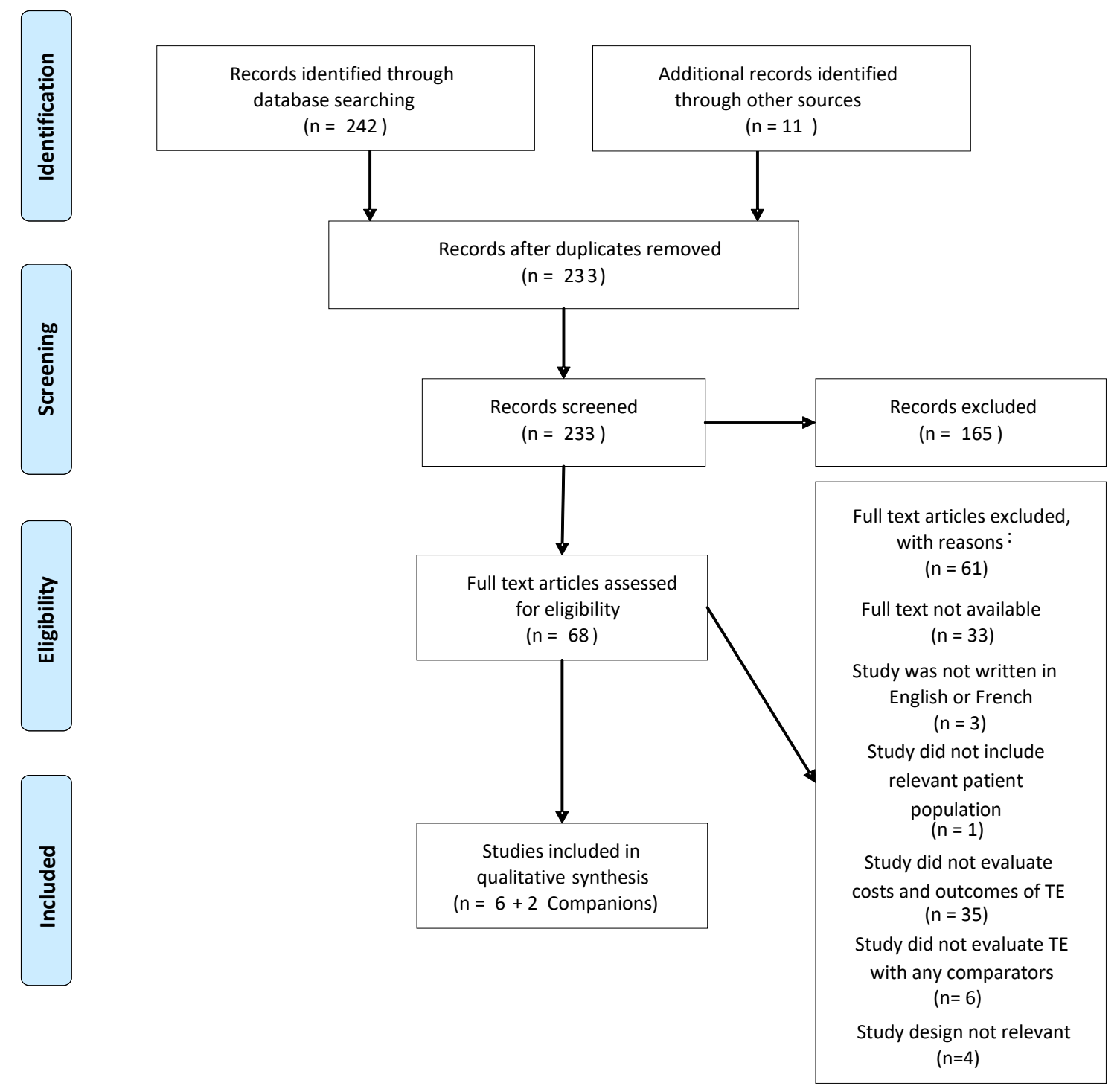

Figure 1: PRISMA 2009 Flow Diagram 


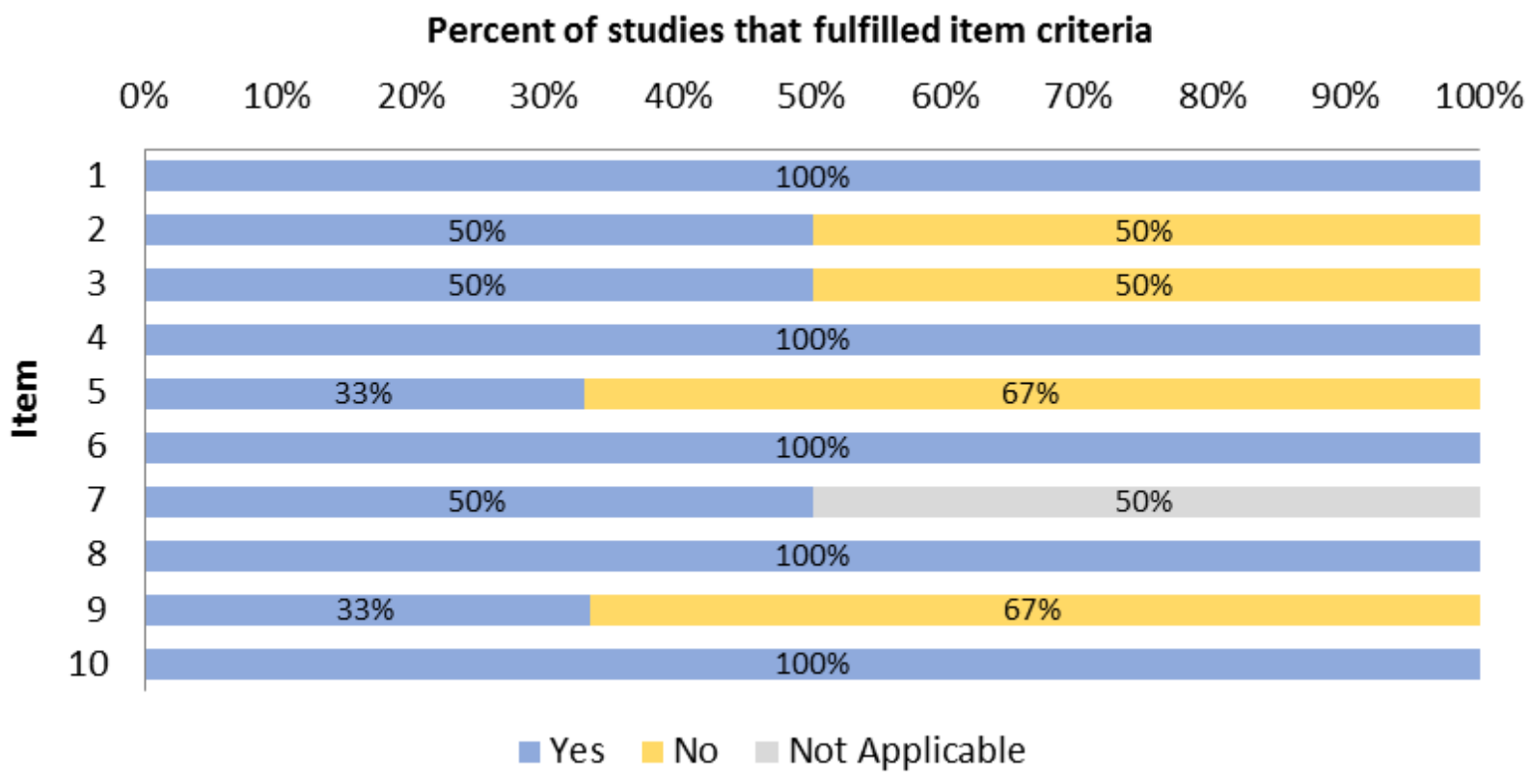

Figure 2: Summary of the methodological quality of included studies assessed by the 10item Drummond's checklist

Items: 1. Well-defined question. 2. Well-described competing alternatives. 3. Established effectiveness. 4. All important and relevant costs and consequences were identified. 5. Measurement was accurately performed. 6. Costs and consequences were valued credibility. 7 . Discounting. 8. Incremental analysis was performed. 9. Allowance made for uncertainty. 10. Discussion 


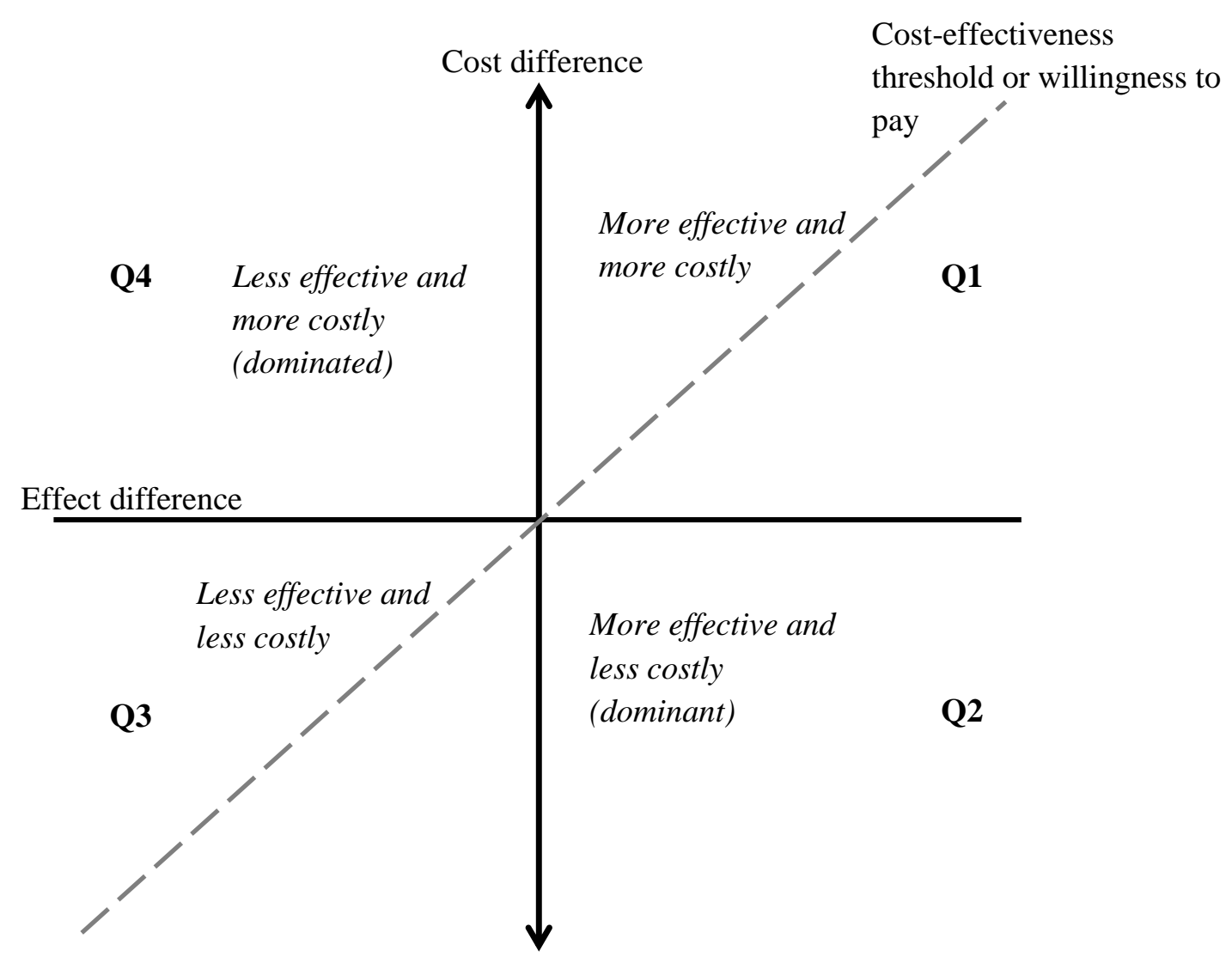

\section{Figure 3: Annotated Cost-Effectiveness Plane}

An ICER could be interpreted by mapping it graphically on a four-quadrant cost-effectiveness plane (Figure 3). (17) The possible outcomes of comparing TE to a comparator are: 1) TE is more effective and more costly (quadrant 1); TE is more effective and less costly, which is noted as 'dominant' (quadrant 2); TE is less effective and less costly (quadrant 3); and TE is less effective and more costly, which is noted as 'dominated' (quadrant 4). Quadrants 1 and 3 require a judgement by the decision maker whether the incremental effectiveness of an intervention (in this case, TE) is large enough to outweigh the incremental cost. This threshold is a decision maker's willingness-topay, and is often specific for each study location (e.g. willingness to pay in Canada has ranged from $\mathrm{C} \$ 20,000$ to $\mathrm{C} \$ 100,000$ per QALY gained). 
Figure 4: Summarized cost-effectiveness findings of cost-effectiveness studies with high methodological quality

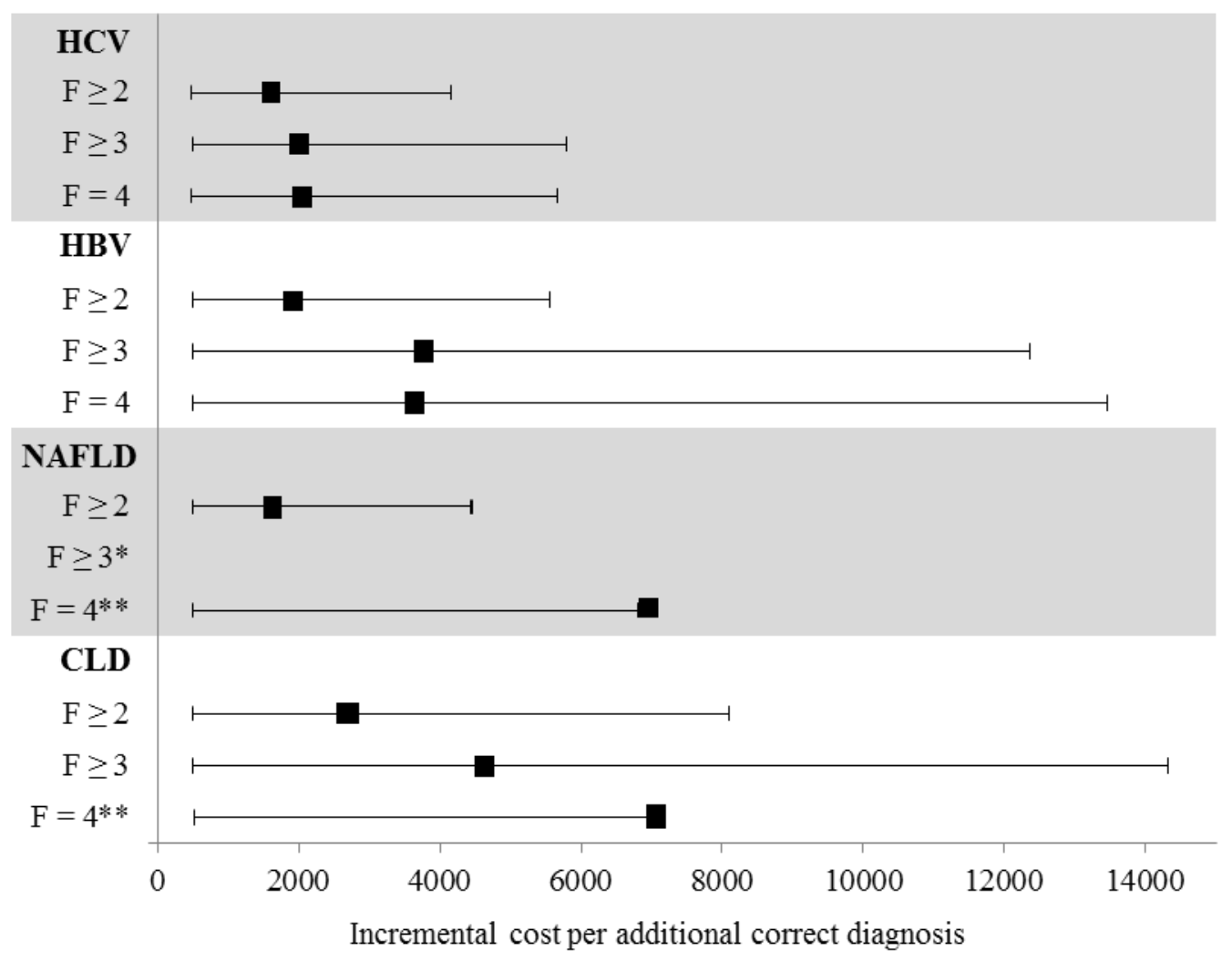

Abbreviations: HBV, hepatitis B virus; HCV, hepatitis C virus; NAFLD, non-alcoholic fatty liver disease; CLD, chronic liver disease

*Data not available from included studies

**Studies found the cost per correct diagnosis to be the indicated range and the upper range was shown to be dominant.

The square of each row represents the base case findings of the most comprehensive cost-effectiveness study to date (23). The ranges represent the combined lower and upper-bound $95 \%$ confidence intervals of all costeffectiveness studies with a methodological quality score of eight or higher $(23,25)$. 
Table 1: Characteristics of the included studies

\begin{tabular}{|c|c|c|c|c|c|c|c|c|}
\hline $\begin{array}{l}\text { Study \& year } \\
\text { (companion) }\end{array}$ & Study design & Perspective & Location & $\begin{array}{l}\text { Cost year } \\
\text { (currency) }\end{array}$ & $\begin{array}{l}\text { Modelling } \\
\text { Method }\end{array}$ & $\begin{array}{l}\text { Sample } \\
\text { size }\end{array}$ & Population & Intervention(s) \\
\hline $\begin{array}{l}\text { Steadman et } \\
\text { al, } 2012(17) \\
\text { (Steadman et } \\
\text { al, } 2013(13))\end{array}$ & $\begin{array}{l}\text { Cost- } \\
\text { effectiveness } \\
\text { Analysis, } \\
\text { (Systematic } \\
\text { review/HTA) }\end{array}$ & $\begin{array}{l}\text { Health care } \\
\text { system }\end{array}$ & Canada & $\begin{array}{l}2010 \\
\text { (Canadian } \\
\text { dollar) }\end{array}$ & $\begin{array}{l}\text { Decision } \\
\text { tree }\end{array}$ & $\begin{array}{l}\text { adult } 14,943, \\
\text { paediatric } 52\end{array}$ & $\begin{array}{l}\text { Adult: HBV, } \\
\text { HCV, } \\
\text { NAFLD, } \\
\text { cholestatic } \\
\text { liver disease, } \\
\text { liver } \\
\text { transplant } \\
\text { Paediatric: } \\
\text { nonalcoholic } \\
\text { steatohepatitis }\end{array}$ & $\begin{array}{l}\text { - TE } \\
\text { - Liver biopsy }\end{array}$ \\
\hline $\begin{array}{l}\text { Canavan et al, } \\
2013 \text { (18) }\end{array}$ & $\begin{array}{l}\text { Cost- } \\
\text { effectiveness } \\
\text { analysis }\end{array}$ & Hospital & $\begin{array}{l}\text { United } \\
\text { Kingdom }\end{array}$ & $\begin{array}{l}2012 \\
\text { (British } \\
\text { pound) }\end{array}$ & $\begin{array}{l}\text { Markov } \\
\text { model }\end{array}$ & $\begin{array}{l}10,000 \\
\text { hypothetical } \\
\text { adult cohort }\end{array}$ & $\begin{array}{l}\mathrm{HCV} \text {-infected } \\
\text { patients }\end{array}$ & $\begin{array}{l}\text { - Intermittent biopsy, followed by } \\
\text { ultrasound and blood test every } \\
\text { six months } \\
\text { - Annual biopsy, followed by liver } \\
\text { cancer screening at } 6 \text {-month } \\
\text { intervals once cirrhosis was } \\
\text { identified } \\
\text { - Replacing intermittent liver } \\
\text { biopsy by TE with confirmation } \\
\text { liver biopsy, followed by liver } \\
\text { cancer screening at } 6 \text {-month } \\
\text { intervals once cirrhosis is } \\
\text { identified } \\
\text { - Annual TE with confirmation } \\
\text { liver biopsy, followed by liver } \\
\text { cancer screening at } 6 \text {-month } \\
\text { intervals once cirrhosis is } \\
\text { identified } \\
\text { - Annual TE as a definitive test, }\end{array}$ \\
\hline
\end{tabular}




\section{Study \& year Study design Perspective Location Cost year Modelling Sample Population Intervention(s) \\ (companion) \\ (currency) Method \\ size}

followed by liver cancer

screening at 6-month intervals

once cirrhosis is identified

- No surveillance of fibrosis stage

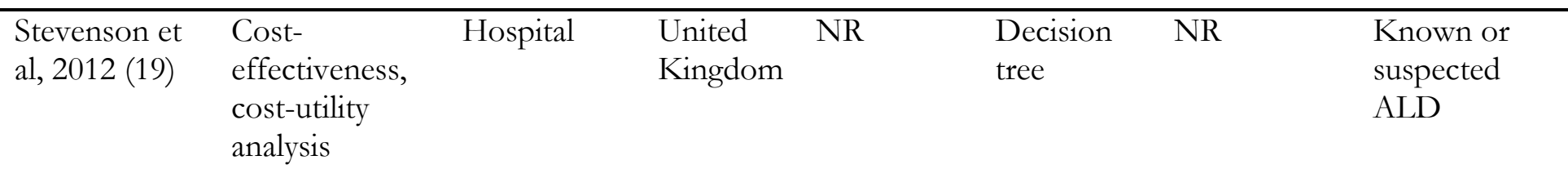

- TE

- FibroTest

- FibroMAX ${ }^{1}$

(Systematic

- Liver biopsy

review /HTA)

\begin{tabular}{lllllll}
\hline $\begin{array}{l}\text { Carlson et al, } \\
2009(16)\end{array}$ & $\begin{array}{l}\text { Cost- } \\
\text { effectiveness } \\
\text { analysis }\end{array}$ & Hospital & $\begin{array}{l}\text { United } \\
\text { States }\end{array}$ & $\begin{array}{l}2005 \\
\text { (US dollar) }\end{array}$ & $\begin{array}{l}\text { Decision } \\
\text { tree }\end{array}$ & $\begin{array}{l}\mathrm{N}=1,000 \\
\text { hypothetical } \\
\text { cohort }\end{array}$
\end{tabular}

\begin{tabular}{|c|c|c|c|c|c|c|c|c|}
\hline $\begin{array}{l}\text { Centre for } \\
\text { Evidence- } \\
\text { based } \\
\text { Purchasing, } \\
2009 \text { (15) }\end{array}$ & $\begin{array}{l}\text { Cost- } \\
\text { effectiveness } \\
\text { analysis } \\
\text { (Systematic } \\
\text { review /HTA) }\end{array}$ & $\begin{array}{l}\text { Health care } \\
\text { system }\end{array}$ & $\begin{array}{l}\text { United } \\
\text { Kingdom }\end{array}$ & $\begin{array}{l}2007 \\
\text { (British } \\
\text { pound) }\end{array}$ & $\begin{array}{l}\text { Decision } \\
\text { tree }\end{array}$ & $\mathrm{NR}$ & $\begin{array}{l}\text { Significant } \\
\text { fibrosis (F2 - } \\
\text { F4) }\end{array}$ & $\begin{array}{ll}\text { - } & \text { liver biopsy } \\
\text { - } & \text { TE } \\
\text { - } & \text { FibroTest } \\
\text { - } & \text { Liver biopsy }\end{array}$ \\
\hline $\begin{array}{l}\text { Crossan et al, } \\
2015(14) \\
\text { (Tsochatzis et } \\
\text { al, } 2014(20) \text { ) }\end{array}$ & $\begin{array}{l}\text { Cost- } \\
\text { effectiveness, } \\
\text { cost-utility } \\
\text { analysis } \\
\text { (Systematic } \\
\text { review /HTA) }\end{array}$ & $\begin{array}{l}\text { Health care } \\
\text { system }\end{array}$ & $\begin{array}{l}\text { United } \\
\text { Kingdom }\end{array}$ & $\begin{array}{l}2012 \\
\text { (British } \\
\text { pound) }\end{array}$ & $\begin{array}{l}\text { Decision } \\
\text { tree and } \\
\text { Markov } \\
\text { model }\end{array}$ & & $\begin{array}{l}\mathrm{HBV}, \mathrm{HCV}, \\
\text { ALD, } \\
\text { NAFLD }\end{array}$ & $\begin{array}{l}\text { - } \mathrm{TE} \\
\text { - FibroTest } \\
\text { - } \text { ARFI } \\
\text { - Other non-invasive tests, such } \\
\text { as Dw-MRI, FibroIndex, }\end{array}$ \\
\hline
\end{tabular}

\footnotetext{
${ }^{1}$ FibroMAX utilizes combined diagnostic tests, including FibroTest, SteatoTest, and NashTest; it uses ten serum markers (Alpha-2-macroglobulin, haptoglobulin, apolipoprotein A1, Gamma-glutamyl transpeptidase (GGT), total bilirubin, ALT, AST, total cholesterol, triglycerids, and blood sugar) combined with age, sex, height and weight of the patient to calculate diagnosis.

${ }^{2}$ Fibrospect II uses three serum markers (hyaluronic acid, metalloproteinase (TIMP-1), and $\alpha 2$-macroglobulin (AMG)) to diagnose severity of fibrosis.
} 


$\begin{array}{llllll}\begin{array}{l}\text { Study \& year } \\ \text { (companion) }\end{array} & \text { Study design } & \text { Perspective Location } & \begin{array}{l}\text { Cost year } \\ \text { (currency) }\end{array} & \begin{array}{l}\text { Modelling Sample } \\ \text { Method }\end{array} & \begin{array}{l}\text { Population } \\ \text { size }\end{array}\end{array}$

contract-enhanced ultrasound, Type IV collagen, etc.

- Liver biopsy

Abbreviations: ALD, alcoholic liver disease; ARFI, acoustic radiation force impulse; APRI, aspartate aminotransferase to platelet ratio index; CDF, correctly diagnosed fibrosis; HBV, hepatitis B virus; HCV, hepatitis C virus; HIV, human immunodeficiency virus; HTA, health technology assessment; ICER, incremental cost-effectiveness ratio; NA, not applicable; NAFLD, nonalcoholic fatty liver disease; NR, not reported; QALY, quality-adjusted life-year; SD, standard deviation; SR, systematic review; TE, transient elastography. 
Table 2: Sensitivity Analysis Descriptions

\begin{tabular}{|c|c|c|c|}
\hline Study & $\begin{array}{c}\text { Modelling } \\
\text { Method }\end{array}$ & Type of Sensitivity Analysis & Parameters \\
\hline $\begin{array}{l}\text { Steadman et al, } \\
2012(17)\end{array}$ & $\begin{array}{l}\text { Decision } \\
\text { tree }\end{array}$ & $\begin{array}{ll}\text { - } & \text { Probabilistic Sensitivity } \\
\text { Analysis (PSA) } \\
\text { - Univariate deterministic } \\
\text { sensitivity analysis }\end{array}$ & $\begin{array}{ll}\text { - } & \text { PSA } \\
\text {-Test sensitivity and } \\
\text { specificity } \\
\text {-Prevalence of fibrosis } \\
\text { - Univariate sensitivity } \\
\text { analysis } \\
\text {-Cost }\end{array}$ \\
\hline $\begin{array}{l}\text { Canavan et al, } \\
2013 \text { (18) }\end{array}$ & $\begin{array}{l}\text { Markov } \\
\text { model }\end{array}$ & $\begin{array}{l}\text { Univariate deterministic } \\
\text { sensitivity analysis }\end{array}$ & $\begin{array}{l}\text {-Natural history data } \\
\text {-Mortality rate } \\
\text {-Cost } \\
\text {-Health utility } \\
\text { - Sensitivity and specificity } \\
\text {-Treatment effectiveness } \\
\end{array}$ \\
\hline $\begin{array}{l}\text { Stevenson et al, } \\
2012(19)\end{array}$ & $\begin{array}{l}\text { Decision } \\
\text { tree }\end{array}$ & $\begin{array}{l}\text { Univariate deterministic } \\
\text { sensitivity analysis }\end{array}$ & $\begin{array}{l}\text {-Health utility } \\
\text {-Test sensitivity and specificity }\end{array}$ \\
\hline $\begin{array}{l}\text { Carlson et al, } \\
2009(16) \\
\end{array}$ & $\begin{array}{l}\text { Decision } \\
\text { tree }\end{array}$ & Alternative scenario analysis & -Test sensitivity and specificity \\
\hline $\begin{array}{l}\text { Centre for } \\
\text { Evidence-based } \\
\text { Purchasing, } \\
2009(15) \\
\end{array}$ & $\begin{array}{l}\text { Decision } \\
\text { tree }\end{array}$ & $\begin{array}{l}\text { Univariate deterministic } \\
\text { sensitivity analysis }\end{array}$ & $\begin{array}{l}\text {-Test sensitivity and specificity } \\
\text {-Prevalence of fibrosis } \\
\text {-Cost }\end{array}$ \\
\hline $\begin{array}{l}\text { Crossan et al, } \\
2015 \text { (14) }\end{array}$ & $\begin{array}{l}\text { Decision } \\
\text { tree and } \\
\text { Markov } \\
\text { model }\end{array}$ & PSA & $\begin{array}{l}\text {-Natural history data, such as } \\
\text { prevalence of chronic liver } \\
\text { disease, risk of progression to } \\
\text { more severe fibrosis stages } \\
\text {-Mortality rate } \\
\text {-Cost } \\
\text {-Health utility } \\
\text {-Test sensitivity and specificity } \\
\text {-Treatment effectiveness }\end{array}$ \\
\hline
\end{tabular}


Table 3: Results of included cost-effectiveness analysis studies (Costs in USD\$, PPP adjusted for 2015)

\begin{tabular}{|c|c|c|c|}
\hline $\begin{array}{l}\text { Name, Year } \\
\text { (Companion) }\end{array}$ & Effectiveness & Costs (USD) & Incremental Cost-Effectiveness Results \\
\hline $\begin{array}{l}\text { Steadman et al, } \\
2012(17) \\
\text { (Steadman et } \\
\text { al, } 2013(13))\end{array}$ & NR & $\begin{array}{l}\text { Total cost } \\
\text { TE (per scan) } \$ 124.33 \\
\text { Liver biopsy } \$ 575.37 \\
\text { Incremental costs } \\
\text { Potential cost savings were approximately } \\
\$ 451.51 \text { to replace each liver biopsy with TE }\end{array}$ & $\begin{array}{l}\text { Incremental cost per correct diagnosis } \\
\text { (\$/correct diagnosis gained); the additional cost } \\
\text { per correct diagnosis using liver biopsy } \\
\text { compared to TE varied from } \$ 1,712 \text { to } \$ 8,768 \text {, } \\
\text { depending on the disease group considered } \\
\text { Hepatitis } B \\
\mathrm{~F} \geq 2 \$ 1,712 ; \mathrm{F} \geq 3 \$ 2,476 ; \\
\mathrm{F}=4 \$ 2,507 \\
\text { Hepatitis } C \\
\mathrm{~F} \geq 2 \$ 2,321 ; \mathrm{F} \geq 3 \$ 4,545 ; \\
\mathrm{F}=4 \$ 4,417 \\
N A F L D \\
\mathrm{~F} \geq 2 \$ 1,868 ; \mathrm{F} \geq 3 \mathrm{NR} \\
\mathrm{F}=4 \$ 8,158 \\
C \text { holestatic liver disease } \\
\mathrm{F} \geq 2 \$ 3,220 ; \mathrm{F} \geq 3 \$ 5,699 ; \\
\mathrm{F}=4 \$ 8,768\end{array}$ \\
\hline $\begin{array}{l}\text { Canavan et al, } \\
2013 \text { (18) }\end{array}$ & $\begin{array}{l}\text { Use of TE provided } \\
\text { an additional } 1.72 \\
\text { unadjusted life-years } \\
\text { compared to the } \\
\text { next best strategy }\end{array}$ & $\begin{array}{l}\text { Lifetime extra cost of } \$ 111.31 \text { per patient } \\
\text { compared to the current UK strategy } \\
\text { (intermittent biopsy of patients with chronic } \\
\text { HCV, with ultrasound and serum alpha- } \\
\text { fetoprotein tests every } 6 \text { months once cirrhosis } \\
\text { is diagnosed) }\end{array}$ & $\begin{array}{l}\text { ICER } \\
\text { TE: } \$ 9,616.29 \text { per QALY } \\
\text { Annual definitive TE was cost-effective using a } \\
\text { threshold of } £ 30,000(\$ 36,000) \text { per QALY }\end{array}$ \\
\hline $\begin{array}{l}\text { Stevenson et } \\
\text { al, } 2012 \text { (19) }\end{array}$ & NR & $\begin{array}{l}\text { Per test } \\
\text { Liver biopsy } \$ 1,311.10-\$ 2,199.83 \\
\text { TE (FibroScan) } \$ 73.30 \\
\text { FibroTest } \$ 73.30\end{array}$ & $\begin{array}{l}\text { FibroScan, using a triage policy, was the only } \\
\text { cost-effective alternative to biopsy using a } \\
\text { QALY threshold of } £ 20,000(\$ 22,000) \text {. } \\
\text { ICER }\end{array}$ \\
\hline
\end{tabular}




\begin{tabular}{|c|c|c|c|}
\hline $\begin{array}{l}\text { Name, Year } \\
\text { (Companion) }\end{array}$ & Effectiveness & Costs (USD) & Incremental Cost-Effectiveness Results \\
\hline
\end{tabular}

Liver biopsy vs. TE: \$104,604.71 per QALY

Sensitivity analysis showed that no procedural alternative was consistently cost-effective compared to biopsy, leading to no definitive recommendations to adopt a non-invasive diagnostic tool.

\begin{tabular}{|c|c|c|c|}
\hline $\begin{array}{l}\text { Carlson et al, } \\
2009 \text { (16) }\end{array}$ & $\begin{array}{l}\text { Approximately } 8 \% \\
\text { false positives and } \\
10 \% \text { false negatives }\end{array}$ & $\begin{array}{l}\text { Average evaluation cost per person } \\
\text { TE } \$ 145.72 \\
\text { Liver biopsy } \$ 1,396 \\
\text { Compared to liver biopsy, there was a cost } \\
\text { savings of } \sim \$ 1,250 \text { per person using TE }\end{array}$ & $\begin{array}{l}\text { Cost savings of } \$ 1,250 \text { per person, but a net } \\
\text { decrease of } 18 \% \text { in the number of people } \\
\text { accurately diagnosed } \\
\text { The average cost per correct diagnosis with TE } \\
\text { compared to liver biopsy was US } \$ 1,219\end{array}$ \\
\hline $\begin{array}{l}\text { Centre for } \\
\text { Evidence- } \\
\text { based } \\
\text { Purchasing, } \\
2009 \text { (15) }\end{array}$ & NR & $\begin{array}{l}\text { Total cost } \\
\text { TE } \$ 20.78 \\
\text { Liver biopsy } \$ 951.78 \text { FibroTest } \$ 82.62 \\
\text { Incremental costs } \\
\text { FibroTest vs. TE: total extra cost of TE for } \\
\text { F2-F4 was } \$ 85,866 \text {; for F4 only was cost- } \\
\text { saving } \\
\text { TE vs. biopsy: total extra cost of biopsy for } \\
\text { F2-F4 was } \$ 490,906 \text {; for F4 only was } \$ 733,992\end{array}$ & $\begin{array}{l}\text { ICER, cost per correctly diagnosed fibrosis gained } \\
\text { FibroTest vs. TE: F2 to F4 \$666.66; F4 only } \\
\text { dominant } \\
\text { TE vs. biopsy: F2 to F4 \$2,922; F4 only } \\
\$ 37,641\end{array}$ \\
\hline $\begin{array}{l}\text { Crossan et al, } \\
2015 \text { (14) } \\
\text { (Tsochatzis et } \\
\text { al, } 2014(20) \text { ) }\end{array}$ & $\begin{array}{l}\text { HBV e antigen-positive } \\
(Q A L Y \text { s) } \\
\text { TE } 11.61 \\
\text { Liver biopsy } 11.41 \\
\text { ARFI } 11.71 \\
\text { FibroTest } 11.62 \\
\text { HBV e antigen-negative } \\
\text { QALYs) } \\
\text { TE } 9.93 \\
\text { Liver biopsy } 9.64\end{array}$ & $\begin{array}{l}\text { HBV e antigen-positive } \\
\text { TE } \$ 94,804.8 \\
\text { Liver biopsy } \$ 91,148 \\
\text { ARFI } \$ 100,184 \\
\text { FibroTest } \$ 95,423 \\
\text { HBV e antigen-negative } \\
\text { TE } \$ 87,608 \\
\text { Liver biopsy } \$ 84,329 \\
\text { ARFI } \$ 93,014 \\
\text { FibroTest } \$ 88,487 \\
\text { HCV }\end{array}$ & $\begin{array}{l}\text { Treating all patients with HCV without } \\
\text { screening for liver fibrosis was the most cost- } \\
\text { effective option: ICER } \$ 13,176 / \text { QALY } \\
\text { At a willingness to pay of } £ 20,000(\$ 22,000) \text {, } \\
\text { TE performed sequentially with another non- } \\
\text { invasive diagnostic test was cost-effective but } \\
\text { the uncertainty was high. }\end{array}$ \\
\hline
\end{tabular}




\begin{tabular}{|c|c|c|c|}
\hline $\begin{array}{l}\text { Name, Year } \\
\text { (Companion) }\end{array}$ & Effectiveness & Costs (USD) & Incremental Cost-Effectiveness Results \\
\hline & $\begin{array}{l}\text { ARFI } 10.10 \\
\text { FibroTest } 9.93 \\
\text { HCV (QALYs) } \\
\text { TE } 14.28 \\
\text { Liver biopsy } 14.03 \\
\text { ARFI } 14.25 \\
\text { FibroTest } 14.30 \\
\text { ALD (QALYs) } \\
\text { TE } 9.02 \\
\text { Liver biopsy } 9.31 \\
\text { FibroTest (low cut- } \\
\text { off): } 9.13 \\
\text { FibroTest (high cut- } \\
\text { off): } 9.03 \\
\text { NAFLD (test positive } \\
\text { cases) } \\
\text { TE } 155 \\
\text { Liver biopsy } 189 \\
\text { FibroTest } 158 \\
\text { ARFI } 170 \\
\text { NAFLD (test negative } \\
\text { cases) } \\
\text { TE } 681 \\
\text { Liver biopsy } 811 \\
\text { FibroTest } 783\end{array}$ & $\begin{array}{l}\text { TE } \$ 56,939 \\
\text { Liver biopsy } \$ 58,452 \\
\text { ARFI } \$ 56,551 \\
\text { FibroTest } \$ 57,992 \\
\text { ALD } \\
\text { TE } \$ 24,011 \\
\text { Liver biopsy } \$ 21,361 \\
\text { FibroTest (low cut-off): } \$ 29,605 \\
\text { FibroTest (high cut-off): } \$ 22,865 \\
\text { NAFLD } \\
\text { TE } \$ 61.20 \\
\text { Liver biopsy } \$ 1,148 \\
\text { FibroTest } \$ 71.17 \\
\text { ARFI } \$ 61.20\end{array}$ & effective: ICER $\$ 1,177 /$ QALY \\
\hline
\end{tabular}

3 'Test positive cases' references the frequency of positive diagnostic reporting for each of the testing tools, where liver biopsy is the gold standard. Similarly, 'test negative cases' references the frequency of negative diagnostic reporting for each of the testing tools, where liver biopsy is the gold standard. 


\begin{tabular}{|c|c|c|c|}
\hline $\begin{array}{l}\text { Name, Year } \\
\text { (Companion) }\end{array}$ & Effectiveness & Costs (USD) & Incremental Cost-Effectiveness Results \\
\hline
\end{tabular}

\footnotetext{
Abbreviations: ALD, alcoholic liver disease; ARFI, acoustic radiation force impulse; APRI, aspartate aminotransferase to platelet ratio index; CDF, correctly diagnosed fibrosis; HBV, hepatitis B virus; HCV, hepatitis C virus; HIV, human immunodeficiency virus; HTA, health technology assessment; ICER, incremental cost-effectiveness ratio; NA, not applicable; NAFLD, nonalcoholic fatty liver disease; NR, not reported; QALY, quality-adjusted life-year; SD, standard deviation; SR, systematic review; TE, transient elastography.
} 